DOI: https://doi.org/10.47405/mjssh.v6i3.681

\begin{tabular}{|c|c|}
\hline 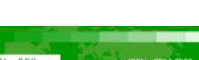 & Malaysian Journal of Social Sciences and Humanities (MJSSH) \\
\hline Malaysian Journal of & Volume 6, Issue 3, March 2021 \\
\hline (MJ-ssH) & e-ISSN : 2504-8562 \\
\hline & $\begin{array}{l}\text { Journal home page: } \\
\text { www.msocialsciences.com }\end{array}$ \\
\hline
\end{tabular}

\title{
Cabaran Mendapatkan Akses Kesihatan dalam kalangan Komuniti Nelayan di Tanjung Dawai, Kedah: Satu Tinjauan Awal
}

\author{
Sofia Haminah Mohd Som ${ }^{1}$, Muhammad Wafi Ramli' ${ }^{1}$, Sharifah Rohayah Sheikh Dawood ${ }^{1}$ \\ ${ }^{1}$ Bahagian Geografi, Pusat Pengajian Ilmu Kemanusiaan, Universiti Sains Malaysia (USM) \\ Correspondence: Sharifah Rohayah Sheikh Dawood (sdawood@usm.my)
}

\begin{abstract}
Abstrak
Makalah ini bertujuan mengenal pasti cabaran yang dihadapi oleh komuniti nelayan di Tanjung Dawai dalam mendapatkan akses kesihatan. Kaedah borang kaji selidik digunakan dengan melibatkan seramai 50 responden yang terdiri daripada ketua isi rumah. Data daripada kaji selidik dianalisis secara statistik deskriptif untuk memperoleh nilai frekuensi dan peratusan. Hasil kajian mendapati bahawa sebilangan besar responden mengalami cabaran yang ketara untuk mendapatkan akses kesihatan dari aspek kewangan untuk mendapatkan rawatan, jarak ke hospital/klinik yang jauh dari tempat tinggal, dan tempoh menunggu yang lama untuk mendapatkan rawatan. Kajian ini dirujuk penting kepada pihak berwajib supaya melaksanakan strategi yang proaktif dalam menaiktarafkan aksesibiliti kesihatan kepada komuniti nelayan di Tanjung Dawai supaya mereka dapat memperoleh ekuiti kesihatan dengan sewajarnya.
\end{abstract}

Kata kunci: aksesibiliti, cabaran, ekuiti, kesihatan

\section{The Challenges in Obtaining Healthcare Access among Fishing Community at Tanjung Dawai, Kedah: A Preliminary Study}

\begin{abstract}
This paper aims to identify the challenges faced by the fishing community in Tanjung Dawai in obtaining health access. The questionnaire method is used involving a total of 50 respondents consisting of heads of household. Data from the questionnaire are analyzed using descriptive statistics to obtain frequency and percentage values. The finding indicates that a large number of respondents are experiencing significant challenges to obtain healthcare access from the aspects of financial capacity to seek healthcare treatment, the distance to hospitals/clinics from their residences are far, and the long waiting period for them to receive healthcare treatment. This study is referred to as important to the authorities to implement proactive strategies in upgrading health accessibility to the fishing community in Tanjung Dawai so that they can obtain health equity accordingly.
\end{abstract}

Keywords: accessibility, challenge, equity, health 


\section{Pengenalan}

Kesihatan merupakan kunci utama kepada kelestarian hidup setiap individu. Merujuk Pertubuhan Kesihatan Sedunia (WHO), kesihatan didefinisikan sebagai keadaan individu yang memiliki kesejahteraan fizikal, mental dan sosial dan bukan sekadar bebas daripada penyakit atau kelemahan. Menurut definisi oleh Dewan Bahasa dan Pustaka (DBP), kesihatan merupakan suatu keadaan atau perihal sihat, kesegaran, kebaikan keadaan badan dan lain-lain. Berdasarkan definisi daripada WHO dan DBP, dapat disimpulkan bahawa kesihatan adalah merujuk kepada tubuh badan yang sihat tanpa sebarang penyakit yang memudaratkan. Ekuiti kesihatan adalah sangat penting dalam kehidupan manusia tanpa mengira kelas sosial dan lokasi geografi. Ekuiti kesihatan didefinisikan sebagai tiada jurang, keistimewaan dan kekurangan dalam kesihatan bagi setiap kelas sosial masyarakat (Braveman \& Gruskin, 2003). Menurut Farley et al. (2020), ekuiti kesihatan ditakrifkan sebagai keadilan dan kesaksamaan yang mana hanya wujud ketika individu memiliki peluang yang sama untuk menjadi sihat. Menurut Khairat et al. (2019), ekuiti kesihatan dikaitkan dengan keadilan sosial yang mana setiap individu mendapat kualiti penjagaan kesihatan yang sama tanpa mengambil kira keadaan sosioekonomi. Hal ini membawa erti di dalam kelas sosial, tidak wujud kumpulan yang mempunyai kelebihan atau kelemahan untuk memperoleh ekuiti kesihatan dari aspek kekayaan, kuasa atau pangkat.

Ketidakseimbangan dalam kesihatan akan memberi kesan terhadap sekumpulan individu yang mempunyai kelas sosial rendah, misalnya golongan miskin, wanita, kumpulan kaum atau etnik, dan agama yang tidak diiktiraf seperti yang berlaku di negara-negara mundur yang dinafikan ekuiti kesihatan mereka. Aksesibiliti kesihatan seharusnya ditawarkan di setiap kawasan secara sama rata di antara bandar dan luar bandar. Kebolehcapaian kepada aksesibiliti kesihatan merupakan antara faktor penting yang membantu rakyat mencapai tahap kesihatan yang baik (Kementerian Kesihatan Malaysia, 2016). Kesamarataan akses kesihatan adalah untuk memastikan semua rakyat mendapat aksesibiliti kesihatan mengikut keperluan tanpa mengira kemampuan mereka untuk membayar bagi aksesibiliti kesihatan tersebut (Kementerian Kesihatan Malaysia, 2016). Oleh yang demikian, mengurangkan jurang kesihatan dapat mewujudkan ekuiti kesihatan yang baik (Khairat et al., 2019).

Masyarakat luar bandar sering kali mengalami halangan dan cabaran dalam mendapatkan aksesibiliti kesihatan. Buarque et al. (2006) menyatakan bahawa isu berhubung kekurangan aspek kesihatan selalu dikaitkan dengan masyarakat luar bandar. Hal ini kemungkinan mempunyai kaitan dengan kesulitan untuk mendapatkan akses kesihatan di luar bandar (Takom et al., 2019). Shakespeare (2012) pula menyatakan bahawa masyarakat yang tinggal di kawasan luar bandar mempunyai keterbatasan kerana kebanyakan aksesibiliti yang ditawarkan sering tertumpu di kawasan bandar. Kesannya, masyarakat luar bandar sering mengalami kesukaran untuk mendapatkan aksesibiliti yang sempurna terutama dari aspek kesihatan (Ramli et al., 2019). Oleh itu, adalah penting untuk menitikberatkan ekuiti kesihatan bagi mengukur tahap kelestarian pembangunan kesihatan sesebuah negara dan juga memastikan semua lapisan masyarakat dapat menikmati aksesibiliti kesihatan yang sewajarnya. Bertitik tolak daripada hal ini, kajian ini dijalankan bertujuan untuk mengenal pasti sama ada komuniti nelayan luar bandar khususnya di Tanjung Dawai mengalami cabaran dalam mendapatkan akses kesihatan ataupun sebaliknya.

\section{Metod Kajian}

Kajian ini telah dijalankan di Kampung Nelayan, Tanjung Dawai. Tanjung Dawai diklasifikasikan sebagai kawasan luar bandar dan merupakan salah sebuah mukim yang terletak dalam daerah Kuala Muda di negeri Kedah. Tanjung Dawai terkenal sebagai destinasi pelancongan yang terkenal dengan hasil makanan laut dan berdekatan dengan sebuah lagi pusat pelancongan, iaitu Pantai Merdeka. Menurut Ramli et al. (2019), pekerjaan komuniti di Kampung Nelayan secara majoritinya adalah nelayan. Kajian ini melibatkan seramai 50 nelayan yang terdiri daripada ketua isi rumah (KIR) sebagai responden. Instrumen kajian adalah melibatkan borang kaji selidik. Borang kaji selidik terbahagi kepada dua bahagian, iaitu (i) profil responden dan (ii) cabaran mendapatkan akses kesihatan. Soalan kaji selidik dibina berdasarkan elemen-elemen cabaran perkhidmatan kesihatan dalam Pelan Transformasi Perkhidmatan Kesihatan yang disediakan oleh Kementerian Kesihatan Malaysia (2015). 
DOI: https://doi.org/10.47405/mjssh.v6i3.681

Soalan-soalan kaji selidik hanya berpandukan pada 3 elemen sahaja daripada 16 elemen cabaran perkhidmatan kesihatan, iaitu pembiayaan kesihatan, infrastruktur dan penyelenggaran serta aksesibiliti perkhidmatan kesihatan yang terhad. Skala Guttman, iaitu YA dan TIDAK digunakan dalam kaji selidik. Data daripada kaji selidik dianalisis menggunakan perisian Statistical Package for the Social Sciences (SPSS) versi 26.0 dengan melibatkan analisis statistik deskriptif bagi memperoleh nilai frekuensi, peratusan dan tahap skor. Interpretasi tahap skor (Jadual 1) ditentukan berdasarkan formula seperti di bawah. Huraian analisis dijelaskan secara deskriptif.

Formula untuk menentukan tahap skor:

Jumlah responden yang menjawab 'YA' × (2) - Jumlah responden yang menjawab 'TIDAK' × (1) 3 (Pembahagian tahap skor)

Contoh: $50(2)-50(1) \div 3=16.6$

Jadual 1: Interpretasi tahap skor

\begin{tabular}{cc}
\hline Skala & Tahap skor \\
\hline $33.4-50$ & Tinggi \\
$16.7-33.3$ & Sederhana \\
$1-16.6$ & Rendah \\
\hline
\end{tabular}

\section{Hasil Kajian dan Perbincangan}

\section{Profil Responden}

Jadual 2 menunjukkan profil responden yang terlibat dalam kajian ini. Berdasarkan jadual tersebut, majoriti responden adalah golongan lelaki Melayu dan beragama Islam. Selain itu, seramai 7 responden (14.0\%) berumur antara 30 hingga 40 tahun, 31 responden (62.0\%) berumur antara 41 hingga 50 dan 12 responden (24.0\%) lagi berumur antara 51 hingga 60 tahun. Dari aspek tahap pendidikan, seramai 9 responden $(18.0 \%)$ tiada pendidikan formal, 15 responden $(30.0 \%)$ mempunyai pendidikan sehingga tamat sekolah rendah dan 26 responden (52.0\%) lagi mempunyai pendidikan sehingga tamat sekolah menengah. Dari aspek pendapatan bulanan pula, seramai 18 responden (36.0\%) berpendapatan bawah RM1200, yakni berada di bawah paras pendapatan minimum yang telah dikuatkuasakan pada tahun 2020, manakala seramai 21 responden (42.0\%) berpendapatan antara RM1201 hingga RM1500 dan 11 responden (22.0\%) lagi berpendapatan antara RM1501 hingga RM2000. Bagi bilangan isi rumah, seramai 15 responden (30.0\%) mempunyai isi rumah antara 4 hingga 6 orang dan 35 responden (70.0\%) lagi mempunyai isi rumah antara 7 hingga 9 orang. Hal ini menunjukkan bahawa sebilangan besar responden mempunyai isi rumah yang ramai.

Jadual 2: Profil responden

\begin{tabular}{lcc}
\hline Kategori & $\begin{array}{c}\text { Jumlah responden } \\
(\mathbf{n}=\mathbf{5 0})\end{array}$ & $\begin{array}{c}\text { Peratusan } \\
(\mathbf{\%})\end{array}$ \\
\hline Umur & & 14.0 \\
$30-40$ & 7 & 62.0 \\
$41-50$ & 31 & 24.0 \\
$51-60$ & 12 & 100 \\
Jantina & & 100 \\
Lelaki & 50 & 100 \\
Kaum & & \\
Melayu & 50 & \\
Agama & & \\
Islam & 50 & \\
\hline
\end{tabular}




\begin{tabular}{lcc}
\hline Tahap pendidikan & 9 & \\
Tiada pendidikan formal & 15 & 18.0 \\
Tamat sekolah rendah & 26 & 30.0 \\
Tamat sekolah menengah & & 52.0 \\
$\begin{array}{l}\text { Pendapatan bulanan } \\
\text { Bawah RM1200 }\end{array}$ & 18 & 36.0 \\
RM1201-RM1500 & 21 & 42.0 \\
RM1501-RM2000 & 11 & 22.0 \\
Bilangan isi rumah (termasuk suami, & & \\
isteri dan anak-anak) & & \\
4-6 orang & 15 & 30.0 \\
7-9 orang & 35 & 70.0 \\
\hline
\end{tabular}

\section{Cabaran Kesihatan dalam kalangan Komuniti Nelayan}

Jadual 3 menunjukkan item-item cabaran kesihatan dalam kalangan komuniti nelayan di Tanjung Dawai. Berdasarkan jadual tersebut, terdapat tiga item cabaran kesihatan yang menunjukkan tahap skor yang tinggi. Item pertama yang mendapat persetujuan tertinggi adalah "masalah kewangan untuk mendapatkan rawatan" dengan mencatatkan seramai 39 responden $(78.0 \%)$ bersetuju dan 11 responden $(22.0 \%)$ tidak bersetuju. Hal ini dipengaruhi oleh pekerjaan mereka sebagai nelayan yang dirujuk tidaklah menyumbang kepada pendapatan bulanan yang tinggi dan sebilangan besar responden mempunyai bilangan isi rumah yang ramai. Jadi, pendapatan bulanan mereka hanya cukup sekadar untuk menampung perbelanjaan isi rumah ditambah lagi dengan bebanan kos perbelanjaan hidup yang semakin tinggi saban hari. Selain itu, masalah kewangan yang berlaku juga bukanlah hanya kerana kos perkhidmatan yang tinggi di hospital/klinik kerajaan/swasta semata-mata, tetapi mereka tidak mempunyai wang yang cukup untuk mendapatkan rawatan kesihatan di hospital/klinik kerajaan/swasta yang terdekat. Hal ini demikian kerana, hospital/klinik kerajaan/swasta yang terdekat berada di bandar Sungai Petani. Sebilangan besar responden tidak mempunyai kenderaan persendirian seperti kereta untuk bergerak ke bandar tersebut.

Jadual 3: Cabaran kesihatan

\begin{tabular}{lccccc}
\hline Item & Ya & \multicolumn{2}{c}{ Tidak } & Tahap \\
Peratusan & N=50 & $\begin{array}{c}\text { Peratusan } \\
\text { (\%) }\end{array}$ & skor \\
\hline $\begin{array}{l}\text { Masalah kewangan untuk mendapatkan } \\
\text { rawatan }\end{array}$ & 39 & 78.0 & 11 & 22.0 & Tinggi \\
$\begin{array}{l}\text { Jarak ke hospital/klinik yang jauh dari } \\
\text { tempat tinggal }\end{array}$ & 37 & 74.0 & 13 & 26.0 & Tinggi \\
$\begin{array}{l}\text { Terpaksa menunggu lama untuk } \\
\text { mendapatkan rawatan }\end{array}$ & 34 & 68.0 & 16 & 32.0 & Tinggi \\
$\begin{array}{l}\text { Rawatan susulan di tempat yang } \\
\text { berlainan }\end{array}$ & 30 & 60.0 & 20 & 40.0 & Sederhana \\
$\begin{array}{l}\text { Waktu temu janji yang tidak sesuai dan } \\
\text { mengganggu waktu bekerja }\end{array}$ & 28 & 56.0 & 22 & 44.0 & Sederhana \\
$\begin{array}{l}\text { Suasana hospital/klinik yang tidak } \\
\text { selesa }\end{array}$ & 27 & 54.0 & 23 & 46.0 & Sederhana \\
$\begin{array}{l}\text { Sukar untuk mendapatkan rawatan } \\
\text { kecemasan }\end{array}$ & 25 & 50.0 & 25 & 50.0 & Sederhana \\
$\begin{array}{l}\text { Kelengkapan rawatan yang disediakan } \\
\text { tidak mencukupi }\end{array}$ & 22 & 44.0 & 28 & 56.0 & Sederhana \\
$\begin{array}{l}\text { Tempat parkir kenderaan yang terhad } \\
\text { Terdapat pengangkutan awam untuk ke } \\
\text { hospital/klinik }\end{array}$ & 16 & 32.0 & 34 & 68.0 & $\begin{array}{l}\text { Rendah } \\
\text { Rendah }\end{array}$ \\
\hline
\end{tabular}


Seterusnya, item kedua yang mendapat persetujuan tinggi adalah "jarak ke hospital/klinik yang jauh dari tempat tinggal" dengan mencatatkan seramai 37 responden $(74.0 \%)$ bersetuju dan 13 responden (26.0\%) tidak bersetuju. Hal ini disebabkan oleh di Tanjung Dawai, tiada hospital/klinik kerajaan/swasta dan farmasi yang disediakan di sana. Untuk mendapatkan akses rawatan di hospital/klinik kerajaan/swasta yang terdekat adalah di bandar Sungai Petani. Jarak perjalanan dari Tanjung Dawai ke bandar Sungai Petani dianggarkan 30 hingga 40 kilometer. Walaupun terdapat Klinik Kesihatan Desa yang disediakan di Tanjung Dawai, namun klinik tersebut dikhususkan untuk kes-kes seperti kehamilan dan rawatan kesihatan untuk ibu dan bayi selepas kelahiran. Tiada akses kesihatan bagi penyakit lain seperti demam sehingga ke penyakit kronik yang disediakan di Tanjung Dawai.

Selanjutnya, item ketiga yang mendapat persetujuan tinggi adalah "terpaksa menunggu yang lama untuk mendapatkan rawatan" dengan mencatatkan seramai 34 responden $(68.0 \%)$ bersetuju dan 16 responden (32.0\%) tidak bersetuju. Hal ini disebabkan oleh hospital/klinik kerajaan/swasta di Sungai Petani merupakan pusat kesihatan yang menjadi tumpuan masyarakat di sebilangan daerah seperti Baling, Yan, Sik dan Kulim. Misalnya, sebarang kes kesihatan yang memerlukan rawatan dan rujukan daripada pihak pakar akan dipindahkan ke hospital/klinik kerajaan/swasta di Sungai Petani.

Di samping itu, terdapat dua item yang menunjukkan tahap skor yang rendah. Item pertama yang menunjukkan tahap persetujuan rendah adalah "tempat parkir kenderaan yang terhad" dengan mencatatkan seramai 16 responden $(32.0 \%)$ bersetuju dan 34 responden $(68.0 \%)$ tidak bersetuju. Hal ini demikian kerana, sebilangan besar responden tidak mempunyai kereta persendirian dan hanya memiliki motosikal sebagai kenderaan utama mereka. Oleh itu, mereka tidak begitu terkesan dengan kemudahan tempat parkir kenderaan di hospital/klinik kerajaan/swasta. Mereka hanya menggunakan motosikal, menyewa kereta, atau meminjam kereta daripada rakan-rakan untuk mendapatkan akses kesihatan di hospital/klinik kerajaan/swasta di Sungai Petani.

Selanjutnya, item kedua yang menunjukkan tahap persetujuan rendah adalah "terdapat pengangkutan awam untuk ke hospital/klinik" dengan mencatatkan seramai 13 responden (26.0\%) bersetuju dan 37 responden $(74.0 \%)$ tidak bersetuju. Hal ini demikian kerana, tiada perkhidmatan pengangkutan awam seperti bas, teksi dan sebagainya yang disediakan di kawasan Tanjung Dawai. Stesen bas dan stesen teksi juga tidak tersedia di Tanjung Dawai kecuali terdapat sebuah jeti yang menyediakan perkhidmatan pengangkutan bot khusus untuk individu atau pelancong yang ingin merentas ke kawasan Pantai Merdeka. Adapun bas dan teksi hanya sekadar menghantar pelancong dari luar kawasan yang ingin melancong ke Tanjung Dawai. Namun kebanyakan pelancong luar akan menggunakan kenderaan sendiri atau menyewa kereta kerana faktor jarak yang jauh dari bandar dan keterbatasan perkhidmatan pengangkutan awam di Tanjung Dawai. Hal ini menunjukkan bahawa

komuniti di Tanjung Dawai mengalami keterbatasan dari aspek pengangkutan awam untuk mereka bergerak ke bandar bagi mendapatkan aksesibiliti-aksesibiliti yang ditawarkan khususnya kesihatan.

\section{Kesimpulan}

Sebagai rumusan, kajian ini berjaya mengenal pasti cabaran utama yang dihadapi oleh komuniti nelayan di Tanjung Dawai dalam mendapatkan akses kesihatan, iaitu masalah kewangan untuk mendapatkan rawatan, jarak ke hospital/klinik yang jauh dari tempat tinggal, dan tempoh menunggu yang lama untuk mendapatkan rawatan. Hal ini secara tidak langsung menunjukkan ekuiti kesihatan dirujuk masih gagal diimplementasikan dalam pembangunan kesihatan masyarakat luar bandar, terutama di kawasan Tanjung Dawai. Adalah penting untuk menyeimbangkan ekuiti kesihatan bagi komuniti di kawasan luar bandar supaya dapat mewujudkan komuniti yang sihat dan sejahtera. Walau bagaimanapun, kajian ini adalah di peringkat awal dan jumlah responden yang terlibat tidaklah begitu besar. Justeru, kajian ini tidak boleh digeneralisasikan untuk semua komuniti nelayan di kawasan kajian. Namun, kajian ini dapat memberi gambaran dan suntikan kepada pihak berwajib supaya dapat melakukan strategi yang proaktif dan komprehensif serta holistik demi menjamin kelestarian ekuiti kesihatan dalam kalangan komuniti luar bandar khususnya nelayan. 


\section{Penghargaan}

Penghargaan ditujukan kepada kepada Universiti Sains Malaysia dan Kementerian Pendidikan Malaysia yang telah membiayai penyelidikan ini melalui Geran Penyelidikan Fundamental FRGS (203/PHUMANITI/6711647) yang bertajuk A Socio-Ecological Approach to Examining Health Behaviour and Health Equity in Urban Areas of Malaysia dan Geran Universiti Penyelidikan (RU) yang bertajuk "Examining the origins and implications of enclave urbanism in the Iskandar Region of Johor, Malaysia” (1001/PHUMANITI/8016024).

\section{Rujukan}

Braveman, P., \& Gruskin, S. (2003). Defining equity in health. Journal of Epidemiology \& Community Health, 57(4), 254-258.

Buarque, C, Spolar, M, dan Zhang, T. (2006). Education and poverty reduction. Review of Education, 52, 219-229.

Farley, J.H., Hines, J., Lee, N.K., Brooks, S.E., Nair, N., Brown, C.L., Doll, K.M., Sullivan, E.J., \& Chapman-Davis, E. (2020). Promoting health equity in the era of COVID-19. Gynecologic Oncology, 158(1), 25-31.

Kementerian Kesihatan Malaysia. (2016). Pelan strategik KKM 2016-2020. Dicapai daripada https://www.moh.gov.my/moh/resources/Penerbitan/Pelan\%20Strategik\%20/20162020/Pelan_Strategik_KKM.pdf

Khairat, S., Haithcoat, T., Liu, S., Zaman, T., Edson, B., Gianforcaro, R., \& Shyu, C.R. (2019). Advancing health equity and access using telemedicine: A geospatial assessment. Journal of the American Medical Informatics Association, 26(8-9), 796-805.

Ramli, M.W., Dawood, S.R.S., \& Som, S.H.M. (2019). Cabaran hidup miskin dalam kalangan komuniti nelayan di Tanjung Dawai, Kedah. Geografia-Malaysian Journal of Society and Space, 15(1), 54-66.

Shakespeare, T. (2012). Disability in developing countries. In Watson, N., Roulstone, A., \& Thomas, C. (Eds.), Routledge handbook of disability studies. Oxon, Routledge.

Takom, L., Bullare, M.I., \& Nawi, N.H.M. (2019). Cabaran dalam mengekalkan kesihatan anak kurang upaya di luar bandar dan pedalaman Sabah. e-Bangi-Journal of Social Sciences and Humanities, 16(5), 1-18. 